\title{
Tetralogy of Fallot: Factors Influencing the Mortality Rate of Total Correction
}

\author{
By Sathaporn Vathayanon, Donald R. Kahn, Aaron M. Stern, \\ Joax M. Sigmann, Pakk W. Willis, III, Burion L. Perky, \\ Marvin M. Kirsh, Pauline W. Ferguson and Herbert Sloan
}

$\mathbf{F}$ ROM 1957 TO THE PRESENT, a total of 215 patients with tetralogy of Fallot underwent operations for total correction using extracorporeal circulation. Although the overall mortality rate was about 13 per cent the rate decreased considerably during the 10 years. The most significant factors influencing the mortality rate were found to be the age of the patient when total correction was performed, the degree of right ventricular outflow obstruction. the associated lesions and the surgical technic. In severe cases the best results were obtained by means of a palliative operation in the early years, followed by total correction when the child was over 6 years.

The diagnosis was confirmed by cardiac catheterization and cineangiography. These findings, as well as other laboratory data, together with the clinical symptoms, postoperative course and necropsy records were carefully reviewed and augmented by follow-up data. There were 123 males and 92 females. Their ages at operation ranged from 17 months to 41 years. The severity of the disease in any given patient depended on the degree of right ventricular obstruction and associated cyanosis.

The patients were grouped as "cyanotic" or "acyanotic" on the basis of cardiac catheterization and angiographic studies. The cyanotic group included those showing obstruction to right ventricular outflow, a ventricular septal defect with a right-to-left shunt and equal pressures in the right and left ventricles. The acyanotic group included those showing less severe obstruction and a balanced shunt or a left-to-right shunt at the ventricular level, with the right ventricular pressure either equal to or slightly lower than that in the left ventricle. There were 154 cyanotic and 61 acyanotic patients. Both infundibular and valvular stenosis were found in 102 patients, infundibular stenosis in 79 , pure valvular stenosis in 21 , pulmonary atresia in 12 and supravalvular stenosis in one. In addition to obstruction of the right ventricular

From the Departments of Surgery, Pediatrics and Medicine, The University of Michigan Medical Center, Ann Arbor, Michigan.

Supported by Research Grants from the Michigan Heart Association.

Sathaporn Vathayanon, M.D.: Instructor in Surgery. Donald R. Kahi, M.D.: Associate Professor of Surgery. AARON M. STERn, M.D.: Professor of Pediatrics. JonN M. Sigmayn, M.D.: Assistant Professor of Pediatrics. Park W. Willis, III, M.D.: Professor of Internal Medicine. Bunton L. Perry, M.D.: Instructor in Pediatrics. Marvin M. Kirsh, M.D.: Resident VI in Surgery. Pauline W. Ferguson, B. A.: Assistant in Research. Hеквент Sloa., M.D.: Professor of Surgery. 

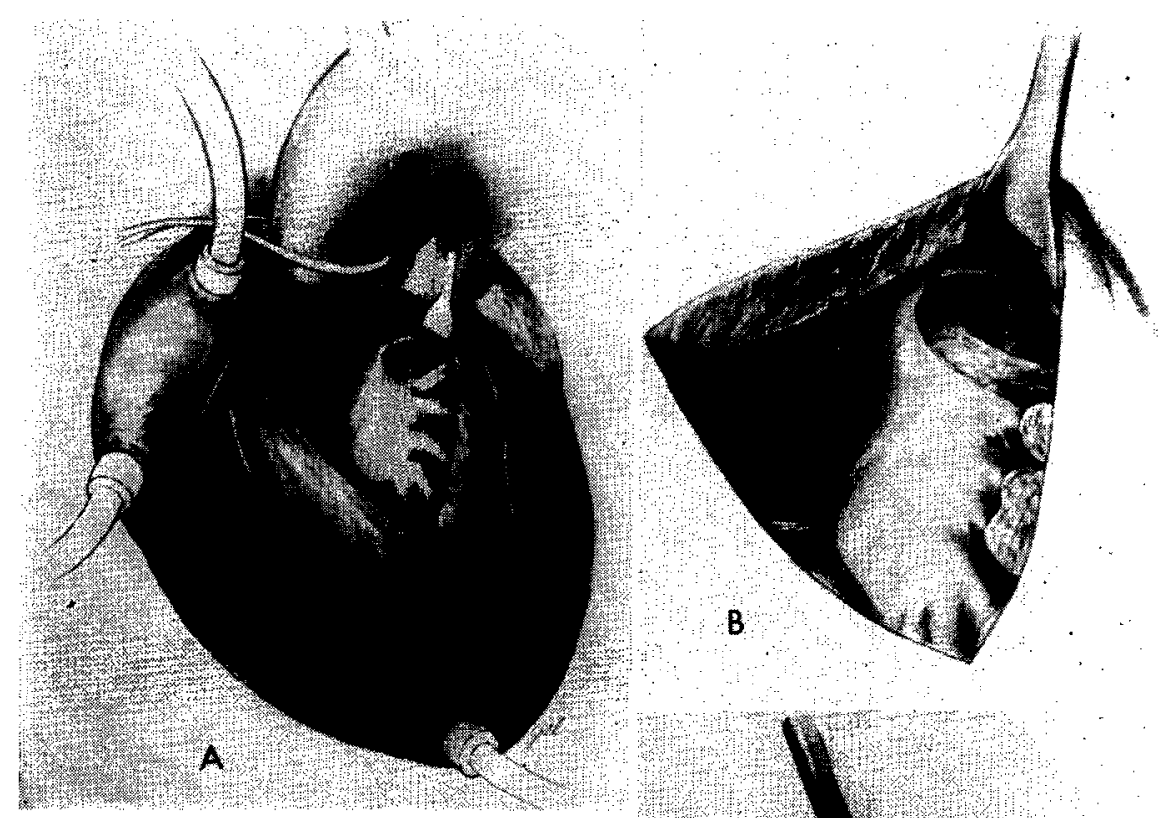

Fig. 1.-A, Surgical exposure of ventricular defect and infundibular stenosis in tetralogy of Fallot. B, Resection of infundibular stenosis and division of hypertrophied trabeculae carneae to create adequate right ventricular outflow tract. C, Closure of ventricular defect by Teflon patch placed with continuous sutures.

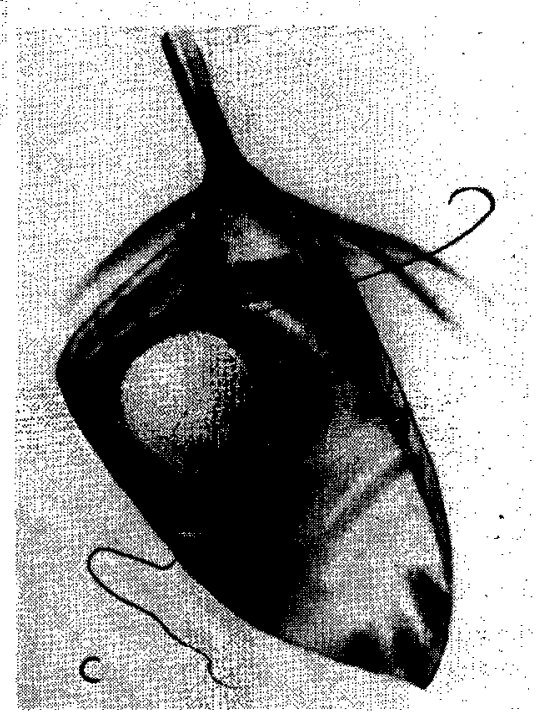

outflow, peripheral stenosis of the pulmonary arteries was found in 18 patients.

The operations for total correction had been preceded by palliative operations in 71 patients. At the time of this first operation the patients' ages were from 3 months to 10 years, with an average of 32 months. The Blalock-Taussig procedure was used in 41 patients, the Potts anastomosis in 15 and transventricular pulmonary valvulotomy in 10. A second pulmonary-systemic anastomosis was necessary in 5 patients because of the failure of the first shunt.

\section{TeChNics}

The exacting preoperative and postoperative care necessary for these patients has been described elsewhere. ${ }^{1,2}$ Cardiopulmonary bypass was carried out by means of a disc oxygenator primed with blood and perfusion rates were between 2200 and $2400 \mathrm{ml} . / \mathrm{sq}$. M./min. Moderate hypothermia (28 to $30 \mathrm{de}$ - 
grees C.) was induced in most cascs. The chest was opened by median sternotomy; the inferior and superior venae cavae were cannulated, and perfusion was carried out through the common femoral artery.

Both transverse and longitudinal ventricular incisions were used (Fig. 1.), the incision being placed to avoid injury to the coronary arteries. Intermittent clamping of the aorta for 5 minute periods was used to improve visibility when necessary. Large ventricular defects were closed with a patch secured by continuous sutures. Such patches were employed in 182 patients, woven Teflon replacing Ivalon for this purpose after 1961.

Infundibular stenosis was relieved by generous resection of hypertrophied muscle, fibrous tissue and trabecular bands along the anterior and lateral wall of the right ventricle. Valvular stenosis was corrected by simple valvulotomy, approached from below or through a separate incision in the common pulmonary artery. Outflow patches were used when the outflow tract obstruction could not be satisfactorily relieved and the right ventricular pressure reduced to $2 / 3$ of the systemic pressure. An outflow patch was also applied if there was pulmonary atresia, if the annulus of the pulmonary valve was small, if there was hypoplasia of the common pulmonary artery or if there was stenosis of the left or right pulmonary artery. In all, 96 patients had an outflow patch placed but the proportion of patients requiring outflow patches has decreased in recent years.

Where an earlier palliative operation had been done, the anastomosis was closed before complete correction of the tetralogy was carried out. The Potts anastomoses usually were closed through the left pulmonary artery under deep hypothermia and circulatory arrest, as described by Kirklin. ${ }^{3}$ The BlalockTaussig shunts were ligated.

\section{Causes of Death}

Among these 215 operations for total correction of the Fallot deformity, 28 resulted in the patient's death in the early postoperative period. Necropsy studies were carried out in 25 patients. The chief causes of death were right ventricular failure and pulmonary edema (Table 1). Factors contributing to the deaths from pulmonary edema included hypoplasia of the left ventricle, inadequate closure of a Potts anastomosis and incomplete closure of the interventricular septal defect. Inadequate cardiac output from right ventricular failure was due either to inadequate relief of the right ventricular outflow obstruction or to peripheral stenoses of the pulmonary arteries. Other immediate cause of death included septicemia, complete heart block, arrhythmia, excessive bleeding, renal failure and cerebral hemorrhage.

There appeared to be a definite relationship between the incidence of death and the ages of the patients at the time of total correction (Table 2). The mortality rate was lowest in the patients between 6 and 14 years of age and highest in those over 15. Among the 98 patients under 5 years, there were 16 deaths in children who had been severely cyanotic and seriously ill.

The factor of cyanosis, as an indication of the severity of thc cardiac disease, was emphasized by the finding that death occurred in only 3 of the 61 acyanotic 
Table 1. - Causes of Hospital Deaths Following Correction of Tetralogy of Fallot

\begin{tabular}{lcc}
\hline & Patients \\
\hline Right ventricular failure & 11 & \\
$\quad$ Inadequate right ventricular & & 7 \\
$\quad$ outtlow tract & & 2 \\
Right ventricular infarct & & 2 \\
Peripheral pulmonary stenosis & 9 & \\
Pulmonary edema & & 4 \\
Small left ventricle & 2 \\
Incomplete closure of Potts anastomosis & 1 \\
Residual interventricular septal defect & 2 \\
Unknown & 3 \\
SBE and septicemia & 1 \\
Complete heart block & 1 \\
Arrhythmia & 1 \\
Bleeding & 1 \\
Renal failure & 1 \\
Cerebral hemorrhage & 28 \\
\hline TOTAL & \\
\hline
\end{tabular}

Table 2. - Relation of Age at the Time of Correction of Tetralogy of Fallot to Mortality

\begin{tabular}{cccc}
\hline Age & Patients & Deaths & Per cent Mortality \\
\hline $1-5$ & 98 & 16 & 15.3 \\
$6-14$ & 83 & 5 & 6.0 \\
$15+$ & 34 & 7 & 20.6 \\
\hline TOTAL & 215 & 28 & 13.0
\end{tabular}

Table 3. - Influence of Previous Shunt on Mortality Following Correction of Tetrology of Fallot in 181 Patients up to 15 Years of Age

\begin{tabular}{cccc}
\hline Shunt & Patients & Deaths & Per cent Mortality \\
\hline With & 57 & 4 & 7.0 \\
Without & 124 & 17 & 13.7 \\
Cyanotic & 71 & 14 & 19.7 \\
Acyanotic & 53 & 3 & 5.6 \\
\hline
\end{tabular}

patients and in 25 of the 154 cyanotic patients. The degree of cyanosis and associated polycythemia reflected the degree of right ventricular obstruction and the volume of flow in the right-to-left shunt. Of the 215 patients, 140 showed hemoglobin levels in the range of 10 to $16 \mathrm{Gm} . / 100 \mathrm{ml}$, and 13 of these patients died after the operation; 75 showed levels of 17 to $25 \mathrm{Gm}$./100 $\mathrm{ml}$., and 15 died. Thus the mortality rate among patients with significant polycythemia was about twice that associated with more normal hemoglobin levels.

The use of a preliminary systemic-pulmonary shunt definitely affected the prognosis (Table 3). Fifty-seven children under 15 years of age had undergone 
an initial shunt to relieve severe cyanosis, and only 4 patients in this group failed to survive the operation for total correction. Among 71 cyanotic patients in this age group without a previous shunt there were 14 deaths. Above the age of 15 there was no significant difference in mortality between patients grouped on the basis of previous shunts.

An analysis of associated lesions indicated that mortality rates were not affected by an interatrial septal defect, a right-sided aortic arch or aortic insufficiency. The operative risk was definitely increased, however, by such conditions as pulmonary atresia, peripheral pulmonary artery stenosis, pulmonary arterial hypertension following a shunt operation, anomalous coronary artery pattern which interfered with the surgical relief of right ventricular obstruction and the presence of bacterial endocarditis.

\section{Follow-Up Studies}

Follow-up data were available in the 187 patients who left the hospital over periods extending from 3 months to 8 years (average: $2 \frac{1}{2}$ years). It was found that 154 patients became asymptomatic after the corrective operation and significant improvement was noted in 13. A second operation was required in 15 patients, usually for residual ventricular defects. Two patients had unsatisfactory results.

There were 5 late deaths among these patients, at intervals ranging from 6 months to 4 years after total correction. One died from congestive heart failure secondary to a residual interventricular septal defect. Another who had complete heart block died suddenly 16 months after the operation, although at necropsy the repair was found to be complete. A third died following the surgical insertion of a Starr-Edwards prosthesis for aortic insufficiency, four years after the correction of tetralogy of Fallot. The fourth patient died following repair of a residual interventricular septal defect 3 years after the corrective operation, and at necropsy it was found that the new ventricular patch had been so large as to obstruct the left ventricular outflow tract. The fifth patient died of pulmonary edema and heart failure 6 months after operation; a postmortem examination was not carried out on this patient.

\section{Discussion}

The total correction of tetralogy of Fallot in young children is associated with high mortality rates, ${ }^{4-7}$ especially if the right ventricular outflow obstruction is severe.

Early operation to establish a systemic-pulmonary artery shunt increases pulmonary blood flow and is often lifesaving. The value of this procedure, which has been greatly strengthened by increasing success with very young patients, lies in its provision for normal growth, enlargement of the pulmonary arteries and left ventricle and restoration of bronchial circulation toward normal. ${ }^{8}$ Taussig" reported that 80 to 86 per cent of these children remained well 5 to 8 years after a Blalock operation, but only 40 per cent remained well after 10 to 13 years. Paul and his associates ${ }^{1 / 3}$ reported that 70 per cent of their patients still showed good results 10 to 13 years after a Potts anastomosis: 
however, pulmonary arterial hypertension had developed in about 20 per cent of these patients.

Polycythemia should be considered an indication of the severity of the cardiac disease and the degree of right ventricular outflow obstruction. The difference in prognosis between acyanotic and cyanotic infants has been clearly demonstrated, ${ }^{5-7}$ and there is a definite relationship between polycythemia and surgical mortality ${ }^{11}$ which is further confirmed by the results of our studies.

Some associated lesions such as interatrial septal defects, patent ductus arteriosus, right-sided aortic arch, left superior vena cava and aortic insufficiency did not affect the hospital mortality in our series. However, several other lesions were associated with a higher mortality; these included peripheral pulmonary stenosis and pulmonary atresia, anomalous right coronary artery, atresia of the common pulmonary artery and pulmonary hypertension following a shunt operation and bacterial endocarditis.

The surgical technic is extremely important in the outcome of any operation to correct tetralogy of Fallot. Improvements in the conduct of extracorporeal circulation have helped to decrease the risk of death. Elimination of right ventricular obstruction and complete closure of the interventricular septal defect are essential. A ventriculotomy which avoids injury to coronary arteries, ${ }^{12}$ the prevention of coronary air embolism and the avoidance of heart block help to improve myocardial function. Complete repair yields excellent clinical results in about 90 per cent of those patients who survive the operation ${ }^{13.14}$; in most instances late deaths are due often to incomplete repair of the cardiac defects.

When right ventricular obstruction is not satisfactorily corrected or when left ventricular function is not adequate, the low-output syndrome is likely to result. This is marked by low arterial pressure, peripheral cyanosis, cold and clammy extremities and oliguria. Metabolic acidosis and renal failure subsequently develop; hypotension progresses and death often follows. There were 27 patients who exhibited this syndrome and 17 died. Myocardial anoxia due to prolonged aortic cross-clamping and coronary artery air embolism may have contributed to this syndrome.

With more careful selection of patients and improvement in the technics of operation, perfusion, and postoperative care, the mortality rate in our series has decreased. Among the 46 patients operated upon during the past 22 months there was only one death.

\section{SUMMARY}

Total correction of tetralogy of Fallot was carried out in 215 patients from 1957 through mid-1967. Twenty-eight patients died during the period of hospitalization following the operation, and 5 died later. The operative mortality rate declined steadily throughout the period, reaching 2.2 per cent in the last 22 months. The major factors determining the outcome of surgical treatment were the age of the patient, the severity of the cardiac deformi- 
ties, the beneficial effects of a prior systemic-pulmonary shunt, associated cardiac lesions, and the surgical technic.

Total correction between the ages of 6 and 14 carries the most favorable prognosis. When young patients are severely cyanotic, it is better to establish a palliative systemic-pulmonary artery shunt, preferably by the Blalock-Taussig technic, and subsequently carry out the total repair when the patient is from 6 to 9 years old. This procedure enhances the child's normal development in the interim and establishes more favorable conditions for the later operation.

\section{SUMMARIO IN INTERLINGUA}

Inter 1957 e medie 1967, 215 patientes experientiava correction total de tetralogia de Fallot al Centro Medical del Universitate Michigan. Le mortalitate al hospital esseva 13 pro cento. Tamen, in le curso del periodo examinate, meliorate technicas de perfusion e de curatura postchinurgic - in combination con un appropriate selection del patientes resultava in un continue declino del mortalitate. Pro le ultime 22 menses illo esseva 2,2 pro cento. Le plus importante factores exercente un influentia super le prognose es le etate del patiente, le severitate de symptomas, le historia de shunting inter le circulationes minor e major, e associate defectos cardiac. Shunting preliminari a objectivo palliative es recommendate pro le severmente cyanotic patiente pediatric de minus que 3 annos de etate. correction total offere le promissa de resultatos maximalmente favorabile in patientes de etates de inter 6 e 14 annos.

\section{REFERENCES}

1. Sloan, H., Morris, J. D., Mackenzie, J., and Stern, A.: Open heart surgery: results in 600 cases. Thorax 17:128, 1962.

2. Sloan, H., and Stern, A.: Problems in the care of patients following open heart surgery. Surg. Clin. N. America 41:1245, 1961 .

3. Kirklin, J. W., and Devloo, R. A.: Hypothermic perfusion and circulatory arrest for surgical correction of tetralogy of Fallot with previously constructed Potts' anastomosis. Dis. Chest 39:87, 1961.

4. Kirklin, J. W., Payne, W. S., Theye, R. A., and DuShane, J. W.: Factors affecting survival after open operation for tetralogy of Fallot. Ann. Surg. 152:485, 1960.

5. Malm, J. R., Boerman, F. O., Jr., Jameson. A. G., Ellis, K., Griffiths, S. P., and Blumenthal, S.: An evaluation of total correction of tetralogy of Fallot. Circulation $27: 805,1963$.

6. Bahnson, H. T., Spencer, F. C., Landtman, B., Wold, M. D., Neil, C. A., and Taussig, H. B.: Surgical treatment and folJow up of 147 cases of tetralogy of Fallot treated by correction. J. Thor. Cardiovasc. Surg. 44:419, 1962 .

7. Hallman, G. I. and Cooley, D. A.: Surgical treatment of tetralogy of Fallot: Experience with indirect and direct technicues. J. Thorac. Cardiov. Surg. 46:419,
1963.

8. Harris, P. D., Bernard, W. F., Gross, R. E., and Nadas, A. S.: The need for systemic-pulmonary artery shunts in the surgical management of tetralogy of Fallot. Circulation 27:801, 1963.

9. Taussig, H. B., Crawford, H., Pelasgonio, S., and Zacharioudakis S.: Ten to thirteen year follow up on patients after a Blalock-Taussig operation. Circulation 25: 630, 1962.

10. Paul, M. H., Miller, R. A., and Potts, W. J.: Long-term results of aortic-pulmonary anastomosis for tetralogy of Fallot. Circulation 23:525, 1961.

11. Leachman, R. D., Hallman, G. L., and Cooley, D. A.: Relationship between polycythemia and surgical mortality in patients undergoing total correction for tetralogy of Fallot. Circulation 32:65, 1965.

12. Gerbode, F., Osborn, J. J., Kerth, W. J., and O'Brien, M. F.: Complete correction of tetralogy of Fallot. Western J. Surg., Obstet. \& Gynec. 72:1, 1964.

13. Kirklin, J. W., Wallace, R. B., McGoon, D. C.. and DuShane, J. W.: Early and late results after intracardiac repair of tetralogy of Fallot. Ann. Surg. 162:578, 1965.

14. Wolf, M. D., Landtman, B., Neill, C. and Taussig, H. B.: Total correction of tetralogy of Fallot. Circulation 31:385, 1965. 